\title{
BILATERAL DISLOCATION OF LENS UNDER COMPLETE VOLUNTARY CONTROL IN MARFAN'S SYNDROME WITH CARDIOVASCULAR ANOMALY ${ }^{* *}$
}

\author{
BY
}

\author{
B. K. DAS GUPTA AND R. K. BASU
}

From the Department of Ophthalmology, Nilratan Sircar Medical College, Calcutta

THE syndrome originally described by Marfan (1896) under the name "dolichostenomalia" was subsequently called "Marfan's syndrome", but Achard (1902) suggested the term "arachnodactyly" because of the spiderlike appearance of the extended fingers.

Since the orginal description of Marfan, well over 300 cases have been recorded in the literature. The condition is characterized by abnormal height, absence of subcutaneous fat, poorly developed musculature, long slender extremities-particularly the fingers and toes-abnormal extensibility of the joints with a tendency to contractures, pigeon or funnel-shaped chest, kyphosis, scoliosis, winging of scapulae, dolichocephalic skull with prominent supra-orbital ridges, high arched palate, malformation of the external ear, pes planus, elevation of the patella, and in some instances congenital abnormalities of the heart and lungs.

Piper and Irvine-Jones (1926) first associated the syndrome with congenital heart disease.

It is now generally accepted that the condition shows a strong hereditary tendency affecting both sexes and transmitted as a dominant characteristic.

Over 60 per cent. of the cases of Marfan's syndrome reported in the literature presented ocular abnormalities, those most frequently found being bilateral subluxated lenses, iridodonesis, and a small pupil dilating poorly with mydriatics. Anomalies of the lids and lashes, nystagmus, and atrophy of the iris stroma were also reported.

Spontaneous dislocation of the subluxated lens (Takei, 1912, Handmann, 1914; Wessely, 1919; and others) is probably due to faulty development of the zonule. The dislocations occur into either the anterior chamber or the vitreous cavity. Sometimes the fibres of the zonule remain attached to the lens capsule, in which case they may become much elongated. More usually, however, the fibres of the zonule became detached from the lens (Maggiore, 1924).

Lenses dislocated into the vitreous cavity can occasionally be coaxed into the anterior chamber by assuming a certain posture and may be imprisoned there by contracting the pupil ("wandering" lens: Duke-Elder, 1940).

A case of Marfan's syndrome is here presented in which cardiac disorder

*This case was demonstrate' at a clinical meeting of the Ophthalmological Society of Bengal on March 31, 1955.

+ Received for publication April 12, 1955. 
was associated with dislocation of the lenses which could be voluntarily moved into either the anterior or posterior chamber.

\section{Case Report}

A girl aged 15 was brought to the Nilratan Sircar Hospital on January 4, 1955. She had had defective vision in both eyes since childhood.

History.-She was an only child and had lost her father when she was 3 and her mother when she was 8 . She had had occasional fainting attacks since the age of 6 , and was apt to tire easily after a little exertion. Since early infancy she had had difficulty in seeing distant objects and had to bring near objects very close to her eyes.

About 6 months previously she had noticed something in each eye which came forwards and obstructed her vision, but could be made to disappear if she assumed a particular posture. She did not mention this to anyone as she was afraid it might cause her to have to undergo an operation, but she had been noticed attempting to make the obstructions disappear from her eyes and had been brought to the hospital by her relatives.

Ophthalmological Examination.-The lids, lashes, conjunctivae, and corneae appeared normal. The anterior chambers were deep and the pupils of normal size $(4 \mathrm{~mm}$.). The pupillary reactions to light and convergence were present but not very brisk. Ocular tension was within normal limits. The iris stroma was healthy except for two patches of atrophy in the left eye and one in the right. In the right anterior chamber a small spherical cataractous lens of irregular contour was seen and in the left anterior chamber a normalsized clear lens which looked like an "oil globule" ovoidal in shape with the long axis horizontal. There was no zonular attachment to either lens.

Viewed through the slit lamp, remnants of zonular fibres showing degenerative changes were seen floating in the pupillary area behind the iris, still attached to the ciliary processes. Some of the zonular fibres showed irregular nodular thickenings (Fig. 1). When the beam from the slit lamp was thrown upon the left lens, the equatorial region showed a golden-yellow reflection (Fig. 2). Fluid vitreous was present in the anterior chamber of both eyes.

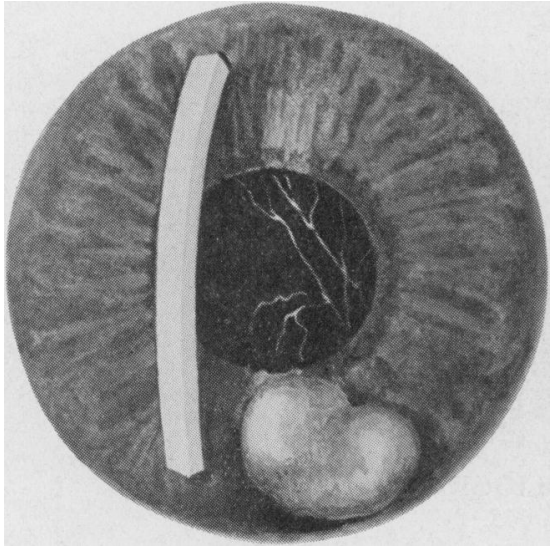

FIG. 1.-Slit-lamp appearance of the right eye showing zonular remnants and patch of atrophy of iris. $(\times 16)$.

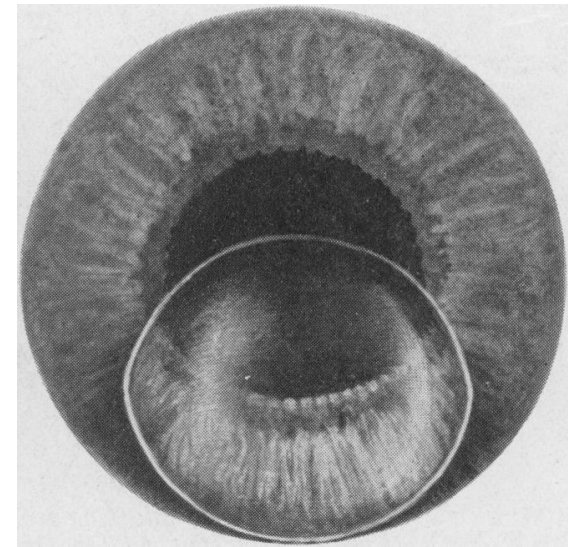

FIG. 2.-Brilliant golden-yellow reflex from margin of displaced lens in left eye. Note magnification of iris tissue as seen through the clear lens.

On application of a 1 per cent. solution of atropine, the pupils dilated moderately.

The patient was then asked to push the lenses back into the vitreous; she threw her head 
back and in a few minutes both the lenses disappeared from view. On being asked to bring the lenses forwards, she lowered her head and in a very short time the lenses came into the anterior chamber. The patient rather liked to retain the lenses within the vitreous cavities as she said that when they were in the anterior chamber she experienced an uncomfortable irritation.

When the lenses were in the vitreous cavities the vision in each eye was $2 \frac{1}{2} / 60$, and with $+10 \mathrm{D}$ sph. correction they improved up to $6 / 36$. No abnormality was detected in the fundi.

General Examination.-The patient was tall and thin with long extremities, tapering hands and toes, prominent supra-orbital ridges, thin and elongated ears, marked upper dorsal scoliosis, and flat feet. The lungs showed nothing abnormal. The heart was of normal size but there was a systolic murmur in the mitral, aortic, mid-precordial, and pulmonary areas. The murmur was most marked in the pulmonary area.

Investigations. - The electrocardiogram and angio-cardiogram showed no abnormality, except that the left ventricle was a little small.

The circulation time, erythrocyte sedimentation rate, and blood count were normal. The Wassermann reaction was negative. The blood pressure, skull measurements, urine, and $x$-ray of heart and oesophagus showed no abnormality.

Treatment.-The right cataractous lens (which measured $5 \times 4 \mathrm{~mm}$.) was removed by operation:

Progress.-About 15 days after the removal of the cataractous right lens, a balloonshaped detachment of the retina developed in the upper temporal quadrant of the retina of the right eye. On account of this complication, it was considered inadvisable to operate on the left eye.

\section{Summary}

(1) A case of Marfan's syndrome with ocular abnormalities and cardiovascular disorder is described, in which the patient had voluntary postural control over the dislocated lenses.

(4) Absence of miosis, dilatation of the pupil by atropine, and absence of rise of tension in the eyes were other noteworthy features.

We wish to thank the Superintendent of the Nilratan Sarkar Hospital for allowing us to publish this case, Dr. Hrishikesh Bose for the electrocardiogram and phonocardiogram, Prof. A. Das for help in taking the angiocardiogram, Dr. D. Bagchi for his co-operation in the cardiovascular investigations, and Mr. A. Das Gupta (by courtesy of Capt. K. Sen) for the paintings.

\section{REFERENCES}

Achard, C. (1902). Bull. Soc. méd. Hôp. Paris, 3 ser, 19, 834.

DUKE-ELDER, S. (1940). "Text-book of Ophthalmology", vol. 3, p. 3243. Kimpton, London. Handmann, M. (1914). Klin. Mbl. Augenheilk., 53, 305.

MAGGIORE, L. (1924). Ann. ottal., 52, 817.

Marfan, A. B. (1896). Bull. Soc. méd. Hôp. Paris, 3 ser, 13, 220.

PIPER, R. K., and IRVINE-JONES, E. (1926). Amer.J. Dis. Child., 31, 832.

TAKEI (1912). Nip. Gank. Zas. (Quoted from Duke-Elder, 1940).

Wessely, K. (1919). Arch. Augenheilk., 85, 63.

\section{ADDITIONAL BIBLIOGRAPHY}

BURCH, F. E. (1936). Arch. Ophthal. (Chicago), 15, 645.

Ellis, R. W. B. (1940). Arch. Dis. Childh., 15, 267.

Futcher, P. H., and SouthWORTH, H. (1938). Arch. intern. Med., 61, 693.

Harrison, J., and Klainer, M. J. (1939). New. Engl. J. Med., 220, 621.

MARVEL, R. J., and GeNOVESE, P. D. (1951). Amer. Heart. J., 42, 814.

RADOS, A. (1942). Arch. Ophthal. (Chicago), $27,477$.

WeILL, G. (1932). Ann. Oculist., Paris, 169, 21.

WEVE, H. (1931). Arch. Augenheilk., 104, 1.

Young, M. L. (1929). Arch. Dis. Childh., 4, 190. 